\title{
DEVELOPMENT OF DESIGN AND MANUFACTURING OF A FIXED WING RADIO CONTROLLED MICRO AIR VEHICLE (MAV)
}

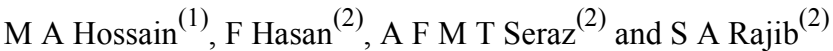

1. Asst. Professor, Department of Mechanical Engineering, Military Institute of Science and Technology.

E-mail: ahossain@mist.edu.bd

2. Student, Department of Mechanical Engineering, Military Institute of Science and Technology.

\begin{abstract}
Micro Air Vehicles (MAVs) are a new type of aircraft maturing day by day and have reached unprecedented levels of growth recently. Similarly to larger Unmanned Air Vehicles (UAVs), MAVs have enormous potential in applications, both military and civilian, like reconnaissance over battlefields and surveillance of urban areas, data relay, air sampling etc. This article describes the development and selection of a fixed wing MAV with the analysis of simulated results. High wing theory with NACA 4412 aerofoil's analytical data has been used to practically predict the performance of the MAV.
\end{abstract}

KEY WORDS: Fixed wing, MAV, NACA 4412, Clark Y.

\subsection{INTRODUCTION}

Ever since mans first powered flight, research efforts have continually pushed the envelope to create machines that are faster and/or larger than ever before. Now, however, there is an effort to design aircraft at the other, largely unexplored end of the spectrum, to design aircraft that are as small and slow as the laws of aerodynamics will permit. The desire for portable, low altitude aerial surveillance has driven the development of aircraft on the scale of small birds. Vehicles in this class of small-scale aircraft are known as Micro Air Vehicles or $M A V s$, and have great potential for applications in surveillance and monitoring tasks in areas either too remote or too dangerous to send human agents. Equipped with small video cameras and transmitters, MAVs can image targets that would otherwise remain inaccessible. MAVs are also capable of carrying an array of sensors to obtain additional information including, for example, airborne chemical or radiation levels.

Current industry trends toward miniaturization of both electronics and communications devices have enabled many recent advances in MAVs. As the technology improves further, more and more tasks are being considered for potential MAV applications. Operational MAVs would enable a number of important civilian missions, including chemical/radiation spill monitoring, forest fire reconnaissance, visual monitoring of volcanic activity, surveys of natural disaster areas, and even inexpensive traffic and accident monitoring. In the military, one of the primary roles for MAVs will be as small-unit battlefield surveillance agents. As such, MAVs can act as an extended set of eyes in the sky for military units in the field. This use of MAV technology is intended to reduce the risk to military personnel and to significantly enhance intelligence capabilities. MAVs are particularly suited for such surveillance tasks, as they are virtually undetectable from the ground. Even within visual range, they often go unnoticed due to their resemblance to birds. This stealth property also lends itself to non-military applications that require unobtrusive surveillance such as wildlife monitoring.

\subsection{Challenges}

There are a number of formidable challenges to designing aircraft at the MAV scale that are not present when designing larger scale vehicles. These challenges fall into three broad categories: (a) aerodynamic efficiency, (b) increased wing loading, and (c) stability and control.

As vehicle size decreases, the viscous effects of the airflow, which are generally ignored in the design of large-scale aircraft, begin to have a significant impact on aerodynamic performance. On the MAV scale, the laminar flow that prevails is easily separated, creating large separation bubbles, especially at higher angles of attack ${ }^{[1]}$. Even the best airfoils on the MAV scale have lift to drag 
ratios almost an order of magnitude smaller than their larger scale counterparts ${ }^{[2]}$.

The challenges related to wing loading are a direct result of the scale of these aircraft. As the wingspan of flying vehicles decreases, the mass of the required structures for the vehicle increase relative to the wing area.

Stability and control presents perhaps the most difficult challenge in deploying operational and usable MAVs. The low moments of inertia of MAVs make them vulnerable to rapid angular accelerations; a problem further complicated by the fact that aerodynamic damping of angular rates decreases with a reduction in wingspan. Another potential source of instability for MAVs is the relative magnitudes of wind gusts, which are much higher at the MAV scale than for larger aircraft. In fact, wind gusts can typically be equal to or greater than the forward airspeed of the MAV itself. From the early flight tests, it has become clear that a very robust control system is indeed required for practical flight missions on the MAV scale.

\subsection{Goal of the Project}

The goal of the project was to develop and exhibit a practical method of building a fixed wing of an MAV. The aircraft described in this study is of a fixed wing design. A fixed wing aircraft is suitable for the above-mentioned category of mission and moreover, it is usually superior in survival if compared to rotorcraft and ornithopters [3, 6]. Because of the lack of experimental data on some of the aerodynamic aspects of MAVs, software base analysis has been carried out in the overall study. The development process is depicted as a flow chart in Fig. 1

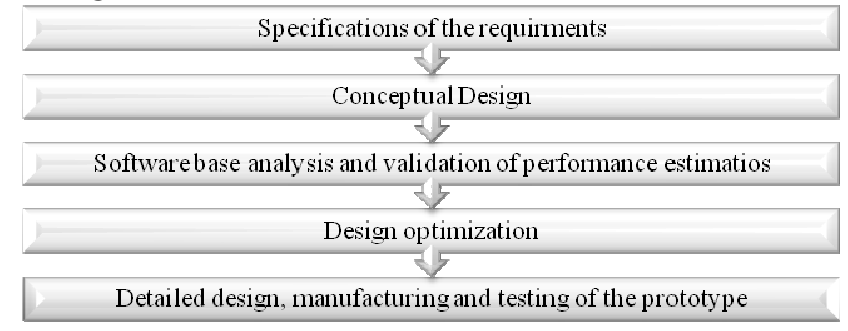

Figure 1: Development process flow chart

\subsection{Selection of Mission Profile}

\subsection{GENERAL REQUIREMENTS}

In this work, the requirements of the outdoor mission have been selected with maximum dimensions of $900 \mathrm{~mm}$ and a maximum take-off weight of $500 \mathrm{~g}$. The mission requirements are to fly within a $0.5 \mathrm{~km}$ radius of the launch spot.

\subsection{Flight Parameters}

Cruise and stall speeds are the next important set of parameters which must be chosen during the mission specification. In this case, cruising speed of $10 \mathrm{~m} / \mathrm{s}$ $(\sim 36 \mathrm{~km} / \mathrm{h})$ has been selected. It may seem rather low, taking atmospheric winds into account ${ }^{[4]}$ it becomes clear that the cruise speed must be well above $10 \mathrm{~m} / \mathrm{s}$ so that winds do not restrict the operations of the MAV to good weather only. But, $4.5-6 \mathrm{~m} / \mathrm{s}$ winds are pretty common in Bangladesh ${ }^{[5]}$ and in case of a rather slow aircraft it might happen that the plane is actually too slow to fly forwards. Stalling speed is selected mainly on the basis of whether the vehicle will be hand-launched or not. In this case, because portability was a major factor, a requirement for stall speed not higher than $6 \mathrm{~m} / \mathrm{s}$ has been made so that the aircraft can be hand-launched and will not require any special equipment.

Once the cruise speed is specified, vehicle endurance can be calculated. With cruise speed of $10 \mathrm{~m} / \mathrm{s}$ it takes about only one minute $(\sim 0.8 \mathrm{~m})$ to fly a $0.5 \mathrm{~km}$ distance. To allow for some extra time (in case of increased wind, reduced battery power at the end of the flight etc.), the design endurance was set to be 5 minutes.

\subsection{CONTROL SYSTEM}

Another important point was to select the way in which MIST-MAV would be controlled. Usually MAVs are controlled in one of 3 ways:

- Fully autonomous

- Pilot-through-vision

- Visual contact

In this case the only viable option was the visual contact system, which means direct control with the pilot looking at the MAV during flying. All the basic requirements are outlined in Table 1 


\begin{tabular}{|c|c|}
\hline Max Weight & $500 \mathrm{~g}$ \\
\hline Max Dimension & $900 \mathrm{~mm}$ \\
\hline Stall Speed & $6 \mathrm{~m} / \mathrm{s}$ \\
\hline Cruise Speed & $10 \mathrm{~m} / \mathrm{s}$ \\
\hline Endurance & 5 minutes \\
\hline Mission Radius & $0.5 \mathrm{~km}$ \\
\hline Control & Visual Contact \\
\hline Payload & $\begin{array}{r}\text { Motor, ESC, Battery, Servo, } \\
\text { RC Receiver }\end{array}$ \\
\hline
\end{tabular}

Table 1: MAV design requirements

\subsection{Wing Design Process}

There are essentially two approaches to wing design. In the direct approach, one finds the planform and twist that minimize some combination of structural weight, drag, and $\mathrm{C}_{\text {Lmax }}$ constraints. The other approach involves selecting a desirable lift distribution and then computing the twist, taper, and thickness distributions that are required to achieve this distribution. The latter approach is generally used to obtain analytic solutions and insight into the important aspects of the design problem, but it is difficult to incorporate certain constraints and offdesign considerations in this approach. The direct method approach is used in this project. Each parameters involving wing design affects drag and structural weight as well as stalling characteristics, battery weight, off-design performance, and many other important characteristics.

\section{Conceptual Design}

\subsection{WING LOADING}

It is an important parameter in aircraft design and it is different for different class of aerial vehicle. Table 2 gives wing loading for typical MAVs.

\begin{tabular}{|c|c|c|}
\hline Model Type & Wing Loading & $\begin{array}{c}\text { Aspect } \\
\text { Ratio }\end{array}$ \\
\hline High Speed & $\begin{array}{c}7-8 \mathrm{~N} / \mathrm{m}^{2}(23-26 \\
\mathrm{oz} / \mathrm{sq} \mathrm{ft}^{2}\end{array}$ & $4-6$ \\
\hline $\begin{array}{c}\text { Moderate } \\
\text { speed sport }\end{array}$ & $\begin{array}{c}4.8-6 \mathrm{~N} / \mathrm{m}^{2}(16-22 \\
\left.\mathrm{oz} / \mathrm{sq} \mathrm{ft}^{\mathrm{f}}\right)\end{array}$ & $6-8$ \\
\hline $\begin{array}{c}\text { Low speed } \\
\text { trainer }\end{array}$ & $\begin{array}{c}3.1-4.8 \mathrm{~N} / \mathrm{m}^{2}(12-16 \\
\left.\mathrm{oz} / \mathrm{sq} \mathrm{ft}^{\mathrm{f}}\right)\end{array}$ & $8-10$ \\
\hline Gliders & $\begin{array}{c}2.4-4.2 \mathrm{~N} / \mathrm{m}^{2}(8-14 \\
\mathrm{oz} / \mathrm{sq} \mathrm{ft})\end{array}$ & $8-15$ \\
\hline
\end{tabular}

Table 2: Wing loading for different types of MAV
Wing loading is calculated through this equation,

wing loading $=\frac{\text { aircraft weight }}{\text { alrcraft area }}$

In this case as the desired MAV can be described as the low speed trainer, therefore wing loading 15 $\mathrm{oz} / \mathrm{sq} \mathrm{ft}$ was taken and as the AUW was assumed as $500 \mathrm{gm}$ (180z), the above equation gives the wing area about $1.2 \mathrm{ft}^{2}$ (172.8 sq in).

Again the aspect ratio can be defined as,

aspect ratio $=\frac{\text { wing span }}{\text { mean chord }}$

From Table 2 aspect ratio was taken as 8 for the design, hence above equation gives wing span 37.56 in and mean chord 4.6 in.

The calculation was carried out on web based software Web o Calc. The result is given in Fig 2.

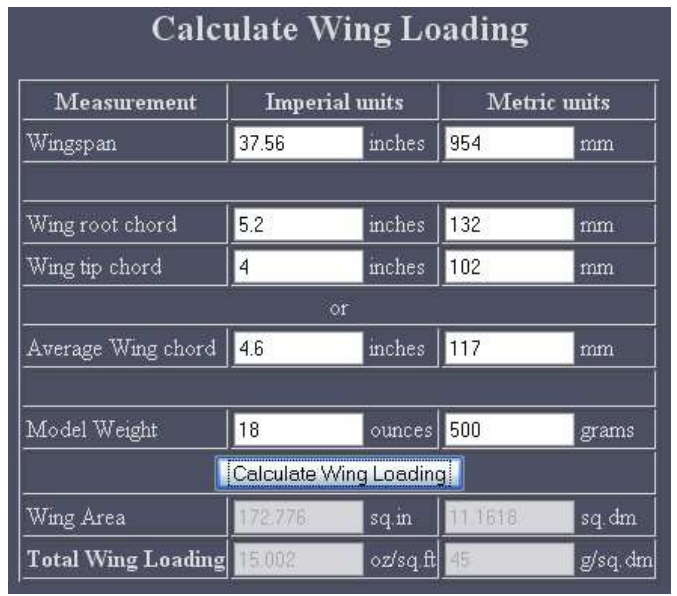

Figure 2: Wing loading calculation

\subsection{Aerofoil Selection}

Two distinct types of aerofoil were selected initially; their comparative analysis and results are outlined in this segment. Analysis of this aerofoil set was evaluated in AeroFoil2.2. Shapes of the two aerofoils are sketched in Figs. 3-4 and characteristics parameters are outlined in the Table 3. 


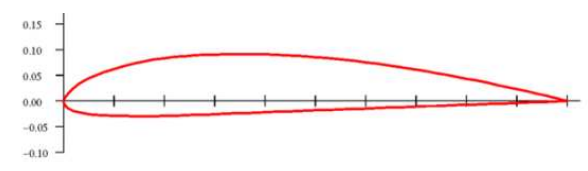

Figure 3 - NACA 4412 Aerofoil

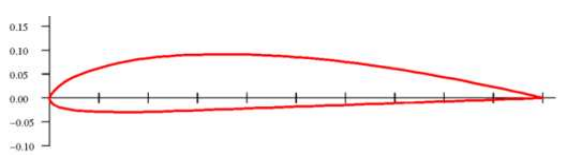

Figure 4 - Clark Y Aerofoil

\begin{tabular}{|c|c|c|}
\hline Parameters & $\begin{array}{c}\text { NACA } \\
\mathbf{4 4 1 2}\end{array}$ & $\begin{array}{c}\text { Clark } \\
\text { Y }\end{array}$ \\
\hline Thickness, \% & $12 \%$ & $11.7 \%$ \\
\hline Camber, \% & $4 \%$ & $3.4 \%$ \\
\hline $\begin{array}{c}\text { Trailing edge } \\
\text { angle }\end{array}$ & $14.4^{\circ}$ & $15.3^{\circ}$ \\
\hline Lower flatness & $76.1 \%$ & $71.8 \%$ \\
\hline $\begin{array}{c}\text { Leading edge } \\
\text { radius }\end{array}$ & $1.2 \%$ & $1.2 \%$ \\
\hline Max $\mathbf{C}_{\mathbf{L}}$ & 1.507 & 1.295 \\
\hline Max $\mathbf{C}_{\mathbf{L}}$ angle & 11 & 8.5 \\
\hline Max L/D & 57.209 & 51.615 \\
\hline Max L/D angle & 5.5 & 7 \\
\hline Max L/D C $\mathbf{L}$ & 1.188 & 1.18 \\
\hline Stall angle & 6 & 8.5 \\
\hline Zero lift angle & -4 & -3.5 \\
\hline
\end{tabular}

Table 3: Comparison characteristics parameters of aerofoil
The above mentioned two configurations were tested at two velocities: $7.72 \mathrm{~m} / \mathrm{s}$ and $10.81 \mathrm{~m} / \mathrm{s}$ which gave Reynolds numbers: 138000 and 193090 at MAC (Eq. 3) for the NACA 4412 and Clark-Y aerofoils. Dependence between coefficients and $R e$ is shown in further analysis so that the characteristics of all the planforms can be compared. $R e=U c / v$

Where:

$U$-Airflow speed, $c$-Wing chord, $v$-Air kinematic viscosity.

The results presented in Figs. 5-8 show a set of three graphs containing coefficient of pressure $C_{p}(x / c)$ at various $\alpha$ for each aerofoil tested. Fig. 9 shows a set of two graphs containing $C_{L}(\alpha), C_{D}(\alpha)$ and $C_{M}(\alpha)$ and Fig. 10 shows another set of two graphs containing $v / V_{\text {air }}(\alpha)$ analysis. Figs. 11 shows drag polar and Figs. 12 shows lift analysis for both the aerofoil. 
NACA 4412 Aerofoil

Reynolds Number: 138,000

Angle of Attack: 0 Degree

Lift Coefficient: 0.461; Drag Coefficient: 0.0125; Pitch Diameter: -0.108 Angle of Zero Lift: -4.151

Aerodynamic Center: $\mathrm{x} / \mathrm{c}=0.2535, \mathrm{y} / \mathrm{c}=-0.0003$; Pitch Coefficient: -0.105

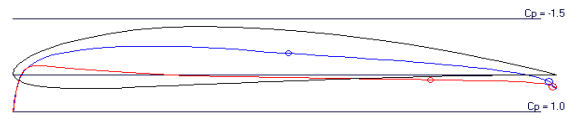

Angle of Attack: 2 Degree

Lift Coefficient: 0.671; Drag Coefficient: 0.0136; Pitch Diameter: -0.110 Angle of Zero Lift: -4.151

Aerodynamic Center: $\mathrm{x} / \mathrm{c}=0.2535, \mathrm{y} / \mathrm{c}=-0.0003$; Pitch Coefficient: -0.105

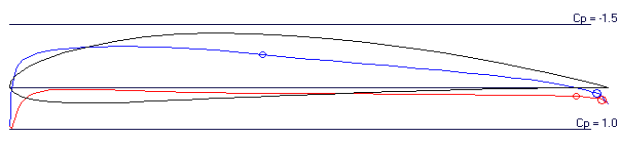

Angle of Attack: 5 Degree

Lift Coefficient: 0.943; Drag Coefficient: 0.0164; Pitch Diameter: -0.113 Angle of Zero Lift: -4.151

Aerodynamic Center: $\mathrm{x} / \mathrm{c}=0,2535 \mathrm{y} / \mathrm{c}=-0.0003$; Pitch Coefficient: -0.105

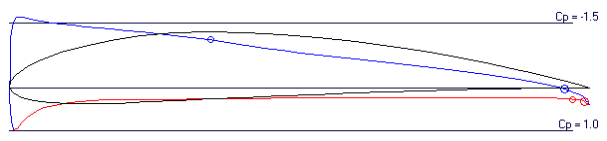

Figure 5: NACA 4412 aerofoil analysis at $R e$ 138,000

CLARK Y Aerofoil

Reynolds Number: 138,000

Angle of Attack: 0 Degree

Lift Coefficient: 0.375; Drag Coefficient: 0.0113; Pitch Diameter: -0.086

Angle of Zero Lift: -3.395

Aerodynamic Center: $\mathrm{x} / \mathrm{c}=0.2527, \mathrm{y} / \mathrm{c}=-0.0002$; Pitch Coefficient: -0.084

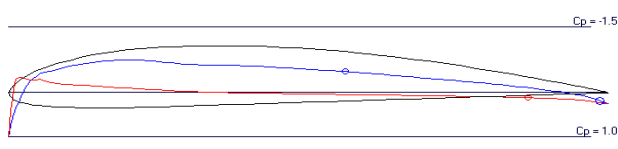

Angle of Attack: 2 Degree

Lift Coefficient: 0.592; Drag Coefficient: 0.0125; Pitch Diameter: -0.087 Angle of Zero Lift: -3.395

Aerodynamic Center: $\mathrm{x} / \mathrm{c}=0.2527, \mathrm{y} / \mathrm{c}=-0.0002$; Pitch Coefficient: -0.084

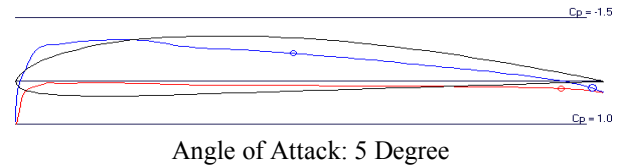

Angle of Attack: 5 Degree

Lift Coefficient: 0.889; Drag Coefficient: 0.0166; Pitch Diameter: -0.089 Angle of Zero Lift: -3.395

Aerodynamic Center: $\mathrm{x} / \mathrm{c}=0.2527, \mathrm{y} / \mathrm{c}=-0.0002$; Pitch Coefficient: -0.084

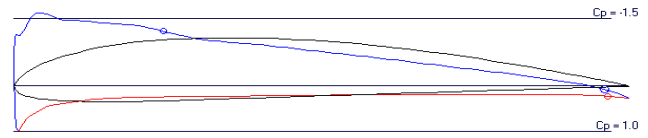

Figure 7: Clark Y aerofoil analysis at $\operatorname{Re} 138,000$
NACA 4412 Aerofoil

Reynolds Number: 193,090

Angle of Attack: 0 Degree

Lift Coefficient: 0.466; Drag Coefficient: 0.0110; Pitch Diameter: -0.108 Angle of Zero Lift: -4.189

Aerodynamic Center: $\mathrm{x} / \mathrm{c}=0.2535, \mathrm{y} / \mathrm{c}=-0.0003$; Pitch Coefficient: -0.105

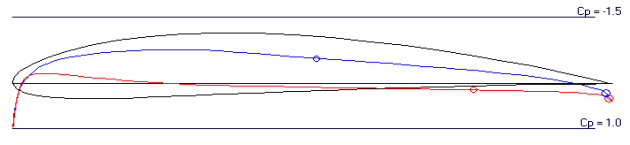

Angle of Attack: 2 Degree

Lift Coefficient: 0.681; Drag Coefficient: 0.0120; Pitch Diameter: -0.109 Angle of Zero Lift: -4.189

Aerodynamic Center: $\mathrm{x} / \mathrm{c}=0.2535, \mathrm{y} / \mathrm{c}=-0.0003$; Pitch Coefficient: -0.105

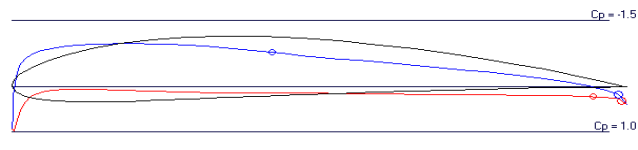

Angle of Attack: 5 Degree

Lift Coefficient: 0.965; Drag Coefficient: 0.0145; Pitch Diameter: -0.112 Angle of Zero Lift: -4.189

Aerodynamic Center: $\mathrm{x} / \mathrm{c}=0.2535, \mathrm{y} / \mathrm{c}=-0.0003$; Pitch Coefficient: -0.105

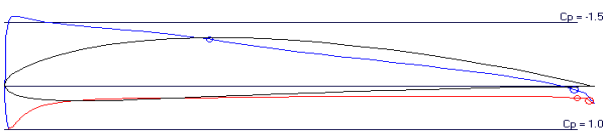

Figure 6: NACA 4412 aerofoil analysis at $\operatorname{Re} 193,090$

\section{CLARK Y Aerofoil}

Reynolds Number: 193,090

Angle of Attack: 0 Degree

Lift Coefficient: 0.387; Drag Coefficient: 0.0099; Pitch Diameter: -0.086 Angle of Zero Lift: -3.419

Aerodynamic Center: $\mathrm{x} / \mathrm{c}=0.2527, \mathrm{y} / \mathrm{c}=-0.0002$; Pitch Coefficient: -0.084

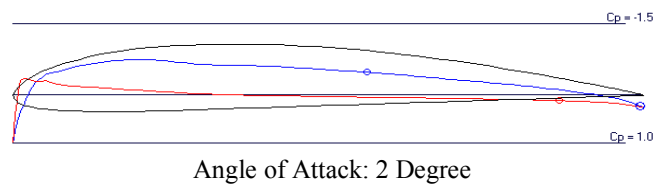

Lift Coefficient: 0.605; Drag Coefficient: 0.0109; Pitch Diameter: -0.087 Angle of Zero Lift: -3.419

Aerodynamic Center: $\mathrm{x} / \mathrm{c}=0.2527, \mathrm{y} / \mathrm{c}=-0.0002$; Pitch Coefficient: -0.084

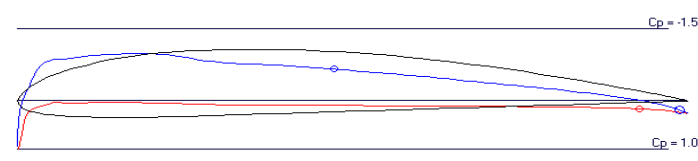

Angle of Attack: 5 Degree

Lift Coefficient: 0.906; Drag Coefficient: 0.0149; Pitch Diameter: -0.089 Angle of Zero Lift: -3.419

Aerodynamic Center: $\mathrm{x} / \mathrm{c}=0.2527, \mathrm{y} / \mathrm{c}=-0.0002$; Pitch Coefficient: -0.084

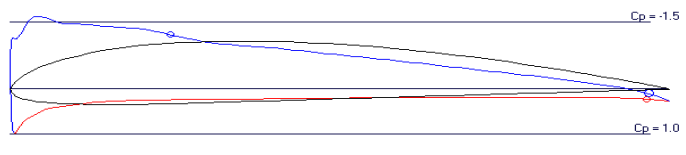

Figure 8: Clark Y aerofoil analysis at $\operatorname{Re} 193,090$ 
NACA 4412 Aerofoil

Coefficient of Lift; Drag Coefficient; Pitch Coefficient

Reynolds Number: 138,000

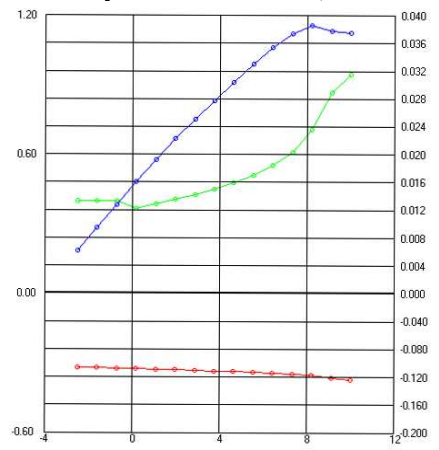

CLARK Y Aerofoil

Coefficient of Lift; Drag Coefficient; Pitch Coefficient Reynolds Number: 138,000

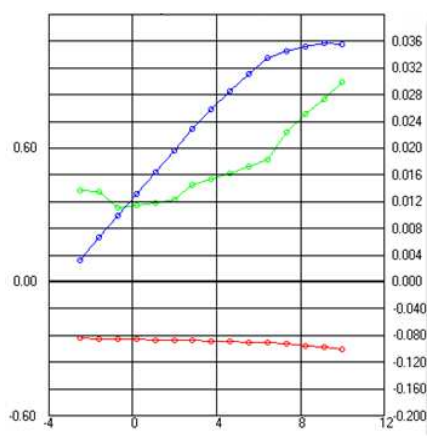

Figure 9: $C_{L}(\alpha), C_{D}(\alpha)$ and $C_{M}(\alpha)$ analysis of NACA 4412 and Clark Y aerofoil
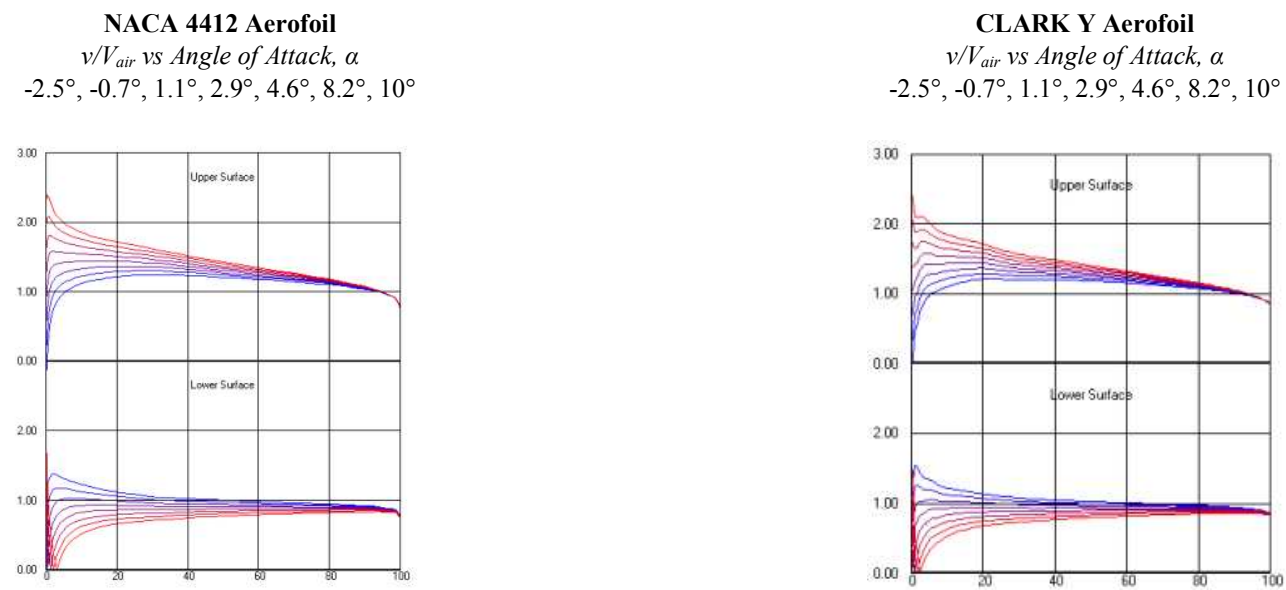

Figure 10: v/Vair ( $\alpha$ ) analysis of NACA 4412 and Clark Y aerofoil
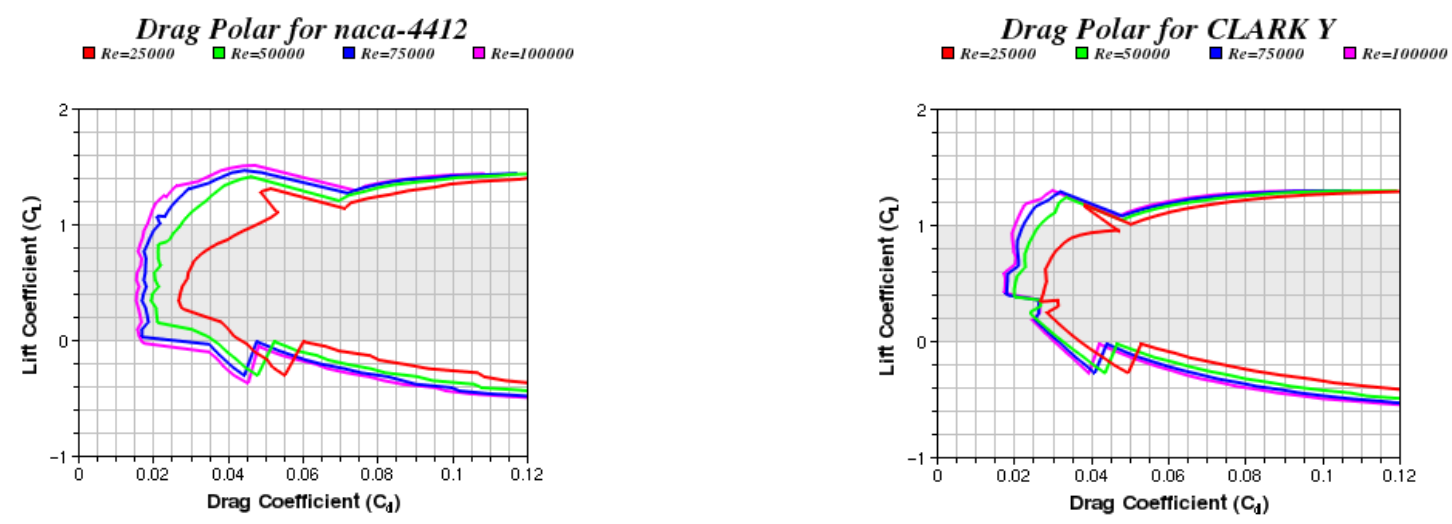

Figure 11: Drag Polar analysis of NACA 4412 and Clark Y aerofoil 

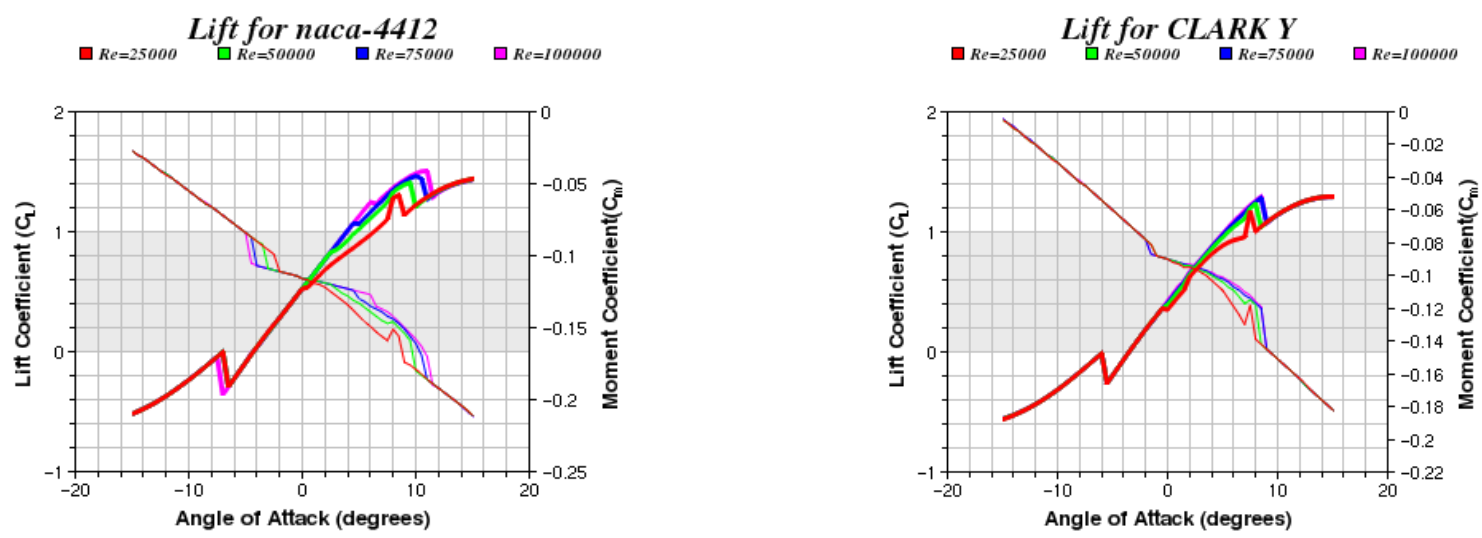

Figure 12: Lift distribution for NACA 4412 and Clark Y aerofoil

\subsection{FINDINGS ON AEROFOIL ANALYSIS}

Results obtained from the graphical analysis of two aerofoils on showed in Fig. $5 \& 7$ and Fig. 6 $\& 8$ are outlined in Table $4 \& 5$ respectively.

Findings are Listed Below

- $\quad$ At low $\boldsymbol{R} \boldsymbol{e}$ Clark Y shows min value of $\boldsymbol{C}_{\boldsymbol{L}}$ where at higher $\boldsymbol{R} \boldsymbol{e}$ it shows similar value of $\boldsymbol{C}_{\boldsymbol{L}}$.

- $\quad$ Relatively NACA 4412 shows good $C_{L}$ values at both low and high $\boldsymbol{R e}$.

- $\quad$ Polar drag configurations showed in Figs. 11 \& $C_{L}(\alpha), C_{D}(\alpha)$ and $C_{M}(\alpha)$ analysis of both aerofoils showed in Fig. 9 established that NACA 4412 gives better $\mathrm{L} / \mathrm{D}$ ratio than Clark $\mathrm{Y}$.

\subsection{Wing Configuration}

Two designs were considered for the comparison, one was the delta wing with a least tip chord of low aspect ratio $(\mathrm{AR}=3)$ and another was the tapered leading-straight trailing wing of moderate aspect ratio $(\mathrm{AR}=5)$. NACA 4412 and CLARK $\mathrm{Y}$ aerofoil were used with these two wings respectively. Table 6 and Figs. 13-14 show the conceptual parameters and design of the two wings respectively.

\begin{tabular}{|c|c|c|c|c|c|c|}
\hline & \multicolumn{2}{|c|}{ Clark Y } & & \multicolumn{2}{c|}{ NACA 4412 } & \\
\hline & $\operatorname{Re} 138000$ & Air Speed 7.72 m/s & & Re 138000 & Air Speed 7.72 m/s & \\
\hline AOA & $C_{L}$ & $C_{D}$ & $C_{M}$ & $C_{L}$ & $C_{D}$ & $C_{M}$ \\
\hline $\mathbf{0}^{\circ}$ & 0.375 & 0.0113 & -0.089 & 0.461 & 0.0125 & -0.108 \\
\hline $\mathbf{2}^{\circ}$ & 0.592 & 0.0125 & -0.087 & 0.671 & 0.0136 & -0.110 \\
\hline $\mathbf{5}^{\circ}$ & 0.889 & 0.0166 & -0.089 & 0.943 & 0.0164 & -0.113 \\
\hline
\end{tabular}

Table 4: Results of aerofoil analysis with $\operatorname{Re} 138000$ and Air Speed 7.72 m/s

\begin{tabular}{|c|c|c|c|c|c|c|}
\hline & \multicolumn{2}{|c|}{ Clark Y } & & \multicolumn{2}{c|}{ NACA 4412 } & \\
\hline & Re 193090 & Air Speed $10.81 \mathrm{~m} / \mathrm{s}$ & & Re 193090 & Air Speed $10.81 \mathrm{~m} / \mathrm{s}$ & \\
\hline AOA & $C_{L}$ & $C_{D}$ & $C_{M}$ & $C_{L}$ & $C_{D}$ & $C_{M}$ \\
\hline $\mathbf{0}^{\circ}$ & 0.387 & 0.0099 & -0.086 & 0.466 & 0.011 & -0.108 \\
\hline $\mathbf{2}^{\circ}$ & 0.605 & 0.0109 & -0.087 & 0.681 & 0.0120 & -0.109 \\
\hline $\mathbf{5}^{\circ}$ & 0.906 & 0.0149 & -0.089 & 0.965 & 0.0145 & -0.112 \\
\hline
\end{tabular}

Table 5: Results of aerofoil analysis with Re 193090 and Air Speed $10.81 \mathrm{~m} / \mathrm{s}$ 


\begin{tabular}{|c|c|c|}
\hline Specification & Delta Wing & Tapered Leading-Straight Trailing \\
\hline Area & $250 \mathrm{in}^{2}$ & $172.8 \mathrm{in}^{2}$ \\
\hline AR & 3 & 8 \\
\hline Span & $27.38 \mathrm{in}$ & $37.56 \mathrm{in}$ \\
\hline $\mathbf{C}_{\mathbf{a v g}}$ & $231.648 \mathrm{~mm}(9.12 \mathrm{in})$ & $179.578 \mathrm{~mm}(7.07 \mathrm{in})$ \\
\hline
\end{tabular}

Table 6: Conceptual Parameters of Wings

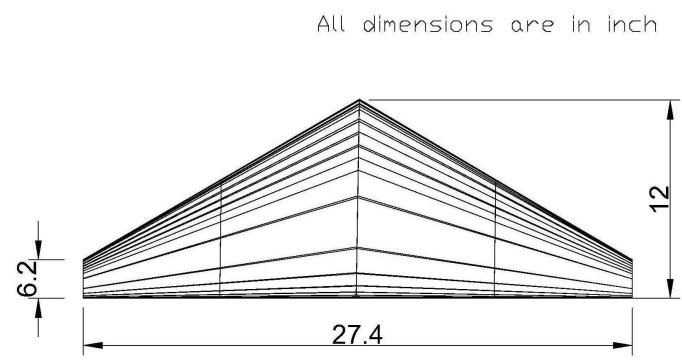

Figure 13: CAD design of wing with Clark Y aerofoil

\subsection{Wing Selection}

Based on the aspect ratio analysis tapered leadingstraight trailing wing was selected of $\mathrm{AR}=8$, the reasons are given below:

Larger induced drag is produced on the aircraft with the smaller wingspan and lower aspect ratio. This property of aspect ratio AR is illustrated in the formula used to calculate the drag coefficient of an aircraft's $C_{d}$

$$
\begin{array}{ll}
C_{d}=C_{d 0}+\left(C_{L}\right)^{2} / & \text { (4)AR } \\
C_{d} & \text { is the aircraft drag coefficient, } \\
c_{d 0} & \text { is the aircraft zero-lift drag coefficient, } \\
C_{E} & \text { is the aircraft lift coefficient, } \\
\pi & \text { is the circumference-to-diameter ratio of } \\
& \text { a circle, } \\
e & \text { is the Oswald efficiency number, } \\
A R & \text { is the aspect ratio. }
\end{array}
$$

Though, there are several reasons why all aircraft do not have high aspect wings:

- $\quad$ Structural: A long wing has higher bending stress for a given load than a short one, which requires stronger structure to withstand.

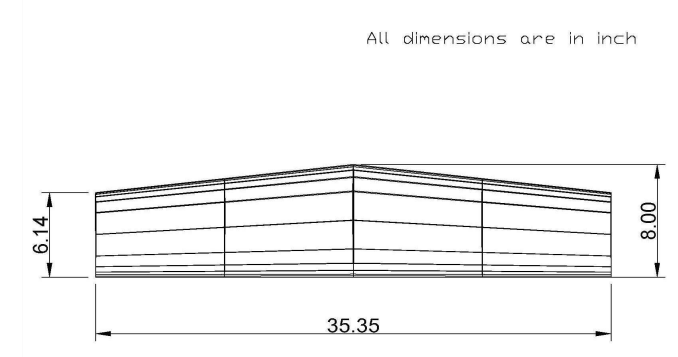

Figure 14: CAD design of wing with NACA 4412 aerofoil

- Maneuverability: a high aspect-ratio wing will have a lower roll rate than one of low aspect ratio.

- Parasitic drag: While high aspect wings create less induced drag, they have greater parasitic drag, (drag due to shape, frontal area, and surface friction). This is because, for an equal wing area, the average chord (length in the direction of wind travel over the wing) is smaller.

But those above mentioned reasons are not applicable for this MAV design; hence the moderate high AR wing was selected of NACA 4412 aerofoil.

\subsection{SIZING OF HORIZONTAL TAIL}

Design of the horizontal tail is so much calculative. Lack of adequate analytical tools prompted an empirical method ${ }^{[7]}$ to be adopted to size the horizontal tail. The empirical rule states that, if an aircraft has a wing of AR of 6 and a tail moment arm (TMA) that is 2.5 times the wing's Mean Aerodynamic Chord (MAC), then a Horizontal Tail Area (HTA) equal to $20 \%$ of the Wing Area (WA) is adequate.

The formula boing ${ }_{\text {. }}$ HTA $=(2.5 \times M A C \times 0.2 \times$ WA $) / T M A$

Where all linear dimensions are in inches and areas are in square inches. Though the aircraft wings did not meet the AR criteria, this formula 
was used. A maximum TMA of $45.26 \mathrm{~cm}$ (17.82”) was feasible for a fuselage length of $83.82 \mathrm{~cm}$ (33"). The HTA thus calculated worked out to be $22.5 \mathrm{in}^{2}$. A tail plane chord of $75 \%$ of wing chord was chosen i.e. $3.45 \mathrm{inch}$ and the tail plane span was fixed at $6.52 \mathrm{inch}$.

\subsection{SizING OF VERTICAL Fin}

Again the empirical rule was used to size the vertical fin which recommends an area of approximately $8 \%$ of wing area as sufficient for the dorsal fin. In the present design, $8 \%$ of the wing area works out to approximately 13.8 sq. in. The fin was sized accordingly.

\subsection{FinAl SPECIFICATIONS}

The final specifications of the MAV are outlined in the Table 7

\begin{tabular}{|c|c|}
\hline Wing Airfoil & NACA 4412 \\
\hline Wing Span & $37.56 \mathrm{in}$ \\
\hline Wing Chord & $4.6 \mathrm{in}$ \\
\hline Wing Area & $172.8 \mathrm{in}^{2}$ \\
\hline Fuselage Length & $83.82 \mathrm{~cm}(33 \mathrm{in})$ \\
\hline Tail plane span & $6.52 \mathrm{in}$ \\
\hline Tail plane Chord & $3.45 \mathrm{in}$ \\
\hline Max AUW & $500 \mathrm{gm}$ \\
\hline Wing loading & $15 \mathrm{oz} / \mathrm{ft}^{2}$ \\
\hline
\end{tabular}

Table 7: Summary

\subsection{SPREAd Sheet BASEd TOOLS for WEIGHT AND CG CALCULATION}

A spreadsheet-based tool was setup to calculate the weight and CG of the aircraft. All off-the-shelf equipment was weighed and their weights were entered in the spreadsheet. For the airframe weight estimation, the first step was to weigh and compute the densities of various types of sheets. The weight of the vehicle was estimated at 500 gm whilst the actual fully equipped aircraft weighed in at $377 \mathrm{gm}$. The CG was estimated 25.8 $\mathrm{cm}$ aft of the motor (datum). The actual CG of the aircraft was found to $23.58 \mathrm{~cm}$ aft of datum i.e. an error of $8.6 \%$. The spreadsheet based tool proved quite useful in fixing the location of various equipment onboard the aircraft. A sample printout of the spreadsheet for aircraft CG calculation is placed in Table 8.

\begin{tabular}{|c|c|c|c|}
\hline Items & $\begin{array}{l}\text { Wt } \\
(\mathbf{g m})\end{array}$ & $\begin{array}{l}\text { Arm } \\
\text { (cm) }\end{array}$ & $\begin{array}{l}\text { Moment (gm- } \\
\text { (m) }\end{array}$ \\
\hline Motor + Plug & 59.92 & 0 & 0 \\
\hline $\begin{array}{c}\text { Motor mount + } \\
\text { Bolts }\end{array}$ & 1.8 & 3.2 & 5.76 \\
\hline Propeller 9x3.8 & 17.87 & -2.5 & -44.68 \\
\hline $\begin{array}{c}\text { 7.2 Volts Battery } \\
\text { pack }\end{array}$ & 59.77 & 20.32 & 1214.53 \\
\hline Receiver & 40.11 & 25.41 & 1019.20 \\
\hline Elevator Servo & 18.51 & 41.91 & 775.76 \\
\hline Aileron Servo & 18.51 & 38.5 & 712.64 \\
\hline Wing & 65.5 & 35.40 & 2318.70 \\
\hline Fins & 21.2 & 78.74 & 1669.29 \\
\hline Fuselage & 49.27 & 41.91 & 2064.91 \\
\hline $\begin{array}{c}\text { Misc linkages and } \\
\text { horns }\end{array}$ & 24.74 & \multicolumn{3}{|c|}{ Distributed } \\
\hline Total & 377.2 & \multicolumn{3}{|c|}{9736.11} \\
\hline CG location & \multicolumn{3}{|c|}{$25.8 \mathrm{~cm}$ aft of motor } \\
\hline
\end{tabular}

Table 8: Data sheet of CG calculation

\subsection{POWER SYSTEM}

Webocalc 1.5.2 is used here to estimate the proper need. Surveying the result, as given the ready flight weight $500 \mathrm{gm}$ and other specific design data, the Webocalc wizard suggested the suitable propeller size ranging from 6.1 to 10 inch. Looking at the thrust comparison result, lowest thrust produces by the $9 \mathrm{x} 6$ propeller is $16.4 \mathrm{oz}$ which is pretty much higher comparing the required $10 \mathrm{oz}$ thrust. As a result propeller size was chosen a smaller one. Other suggested power system equipments were chosen according to the result. Table 9 shows the final selection of the parts with the brand name.

\begin{tabular}{|c|c|}
\hline Motor & $\begin{array}{c}\text { EnerG Brushless Motor (C28-08 } \\
\text { 1360RPM/V) }\end{array}$ \\
\hline \multirow{2}{*}{ ESC } & $\begin{array}{c}\text { E-PRO SP20A-BEC-AIR Brushless/ } \\
\text { Controller }\end{array}$ \\
\hline Battery & Flightpower EVOLITE-0800 2S \\
\hline Propeller & APC 9 x3.8 \\
\hline Receiver & Futaba FP-R115F \\
\hline Servo & Futaba S-3117 \\
\hline Transmitter & Futaba 4VF-FM \\
\hline
\end{tabular}

Table 9: List of parts 


\subsection{IN-FLIGHT ANALYSIS}

In-flight analysis were carried out into MotoCalc to find the optimum MAV's performance and mission constraints. Fig. 14 shows the complete flight analysis of the designed prototype with selected power system components. Findings from the flight analysis are following:

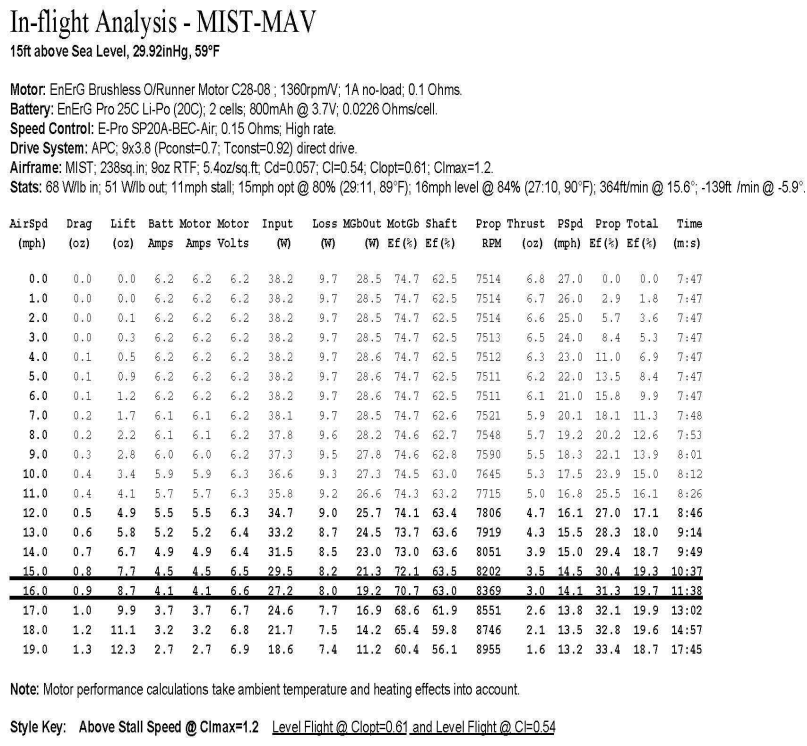

Figure 15: In-Flight analysis

\subsection{Aerodynamic Notes}

- $\quad$ The static pitch speed $(27 \mathrm{mph})$ is within the range of approximately 2.5 to 3 times the model's stall speed (11 $\mathrm{mph})$, which is considered ideal for good performance.

- $\quad$ With a wing loading of $5.4 \mathrm{oz} / \mathrm{sq}$. $\mathrm{ft}$, a model of this size will have very sedate flying characteristics. It will be suitable for relaxed flying, in calm or very light wind conditions.

- The static thrust $(6.8 \mathrm{oz})$ to weight $(9 \mathrm{oz})$ ratio is $0.76: 1$, which will result in very short take-off runs, no difficulty taking off from grass surfaces (assuming sufficiently large wheels), and steep climb-outs.

- At the best lift-to-drag ratio airspeed, the excess-thrust $(2.1 \mathrm{oz})$ to weight $(9 \mathrm{oz})$ ratio is $0.24: 1$, which will give good climbs and acceleration. This is a good in-flight thrust to weight ratio for a basic trainer.

\subsection{POWER SYSTEM NOTES}

- The full-throttle motor current at the best lift-to-drag ratio airspeed (4.1 amp) is lower than the motor's maximum efficiency current (8.1amp). A higher current level would improve system efficiency.

- Current can be increased by using more cells, a larger diameter or higher pitched propeller, a lower gear ratio, or some combination of these methods.

\subsection{StABILITY}

Primary concerns for the MAV were static pitch and roll stability. Dynamic stability was not considered due to complexity, time constraints, and the assumption that static stability would provide acceptable dynamic stability. Two analyses were carried out, these are:

- static pitch stability analysis

- roll stability analysis

\subsection{Structural Material SElEction}

There are a few basic qualities that were desired in materials used to build the MAV that was used in the selection of materials. They are:

- Light weight: First and for most the material needs to be very light.

- Crash resistant: The MAV should be able to survive several crashes before any serious repair is necessary.

- Structurally sound: The material should be strong enough to maintain its shape during normal flight.

- Simple to construct: It should be possible to make an entire MAV structure in 4-6 hours.

- Easy to repair: If damage occurs, it should be possible to fix easily, in order that the most can be learn from each model.

\subsection{DETAILED FABRICATION}

The manufacturing was to be done using typical RC modeling techniques, with $35 \mathrm{~mm}$ EPS (Expanded Polystyrene Foam) and covered with heat shrinkable polyurethane film. The fuselage was constructed as simple rounded structure and 
was sized to enable installation of all the onboard equipment. Heat shrinkable polyurethane film was applied to the surface of the all structures and

\begin{tabular}{|c|c|}
\hline Items & $m[g]$ \\
\hline Misc & 74 \\
\hline Motor & 43 \\
\hline Battery & 51 \\
\hline $\begin{array}{c}\text { Speed } \\
\text { Controller }\end{array}$ & 22 \\
\hline Receiver & 30 \\
\hline Servos (2) & 17 \\
\hline Propeller & 8 \\
\hline Airframe & 255 \\
\hline Total & 500 \\
\hline
\end{tabular}

Table 10: MIST-MAV's final weight breakdown

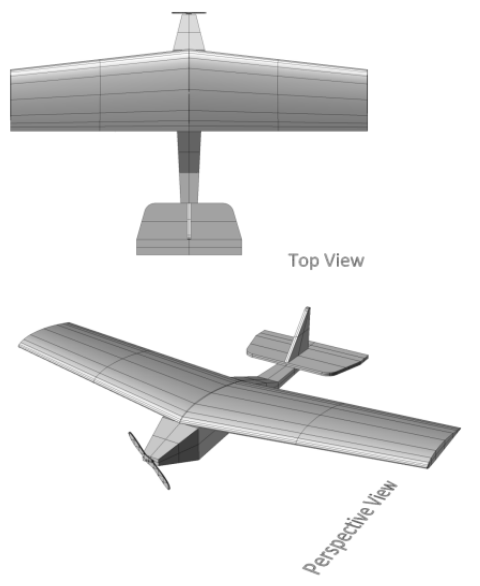

Heat Gun (king). Wing was attached using rubber bands and can be dismantled easily.

The final weight breakdown is shown in the Table 10 and Fig. 16

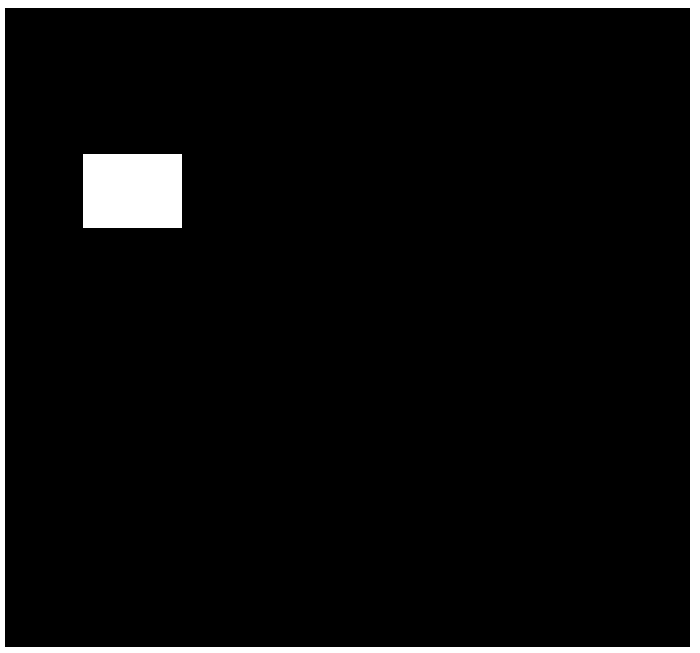

Figure 16: Layout of final weight breakdown

Figure 17: 3D Drawings of an MAV
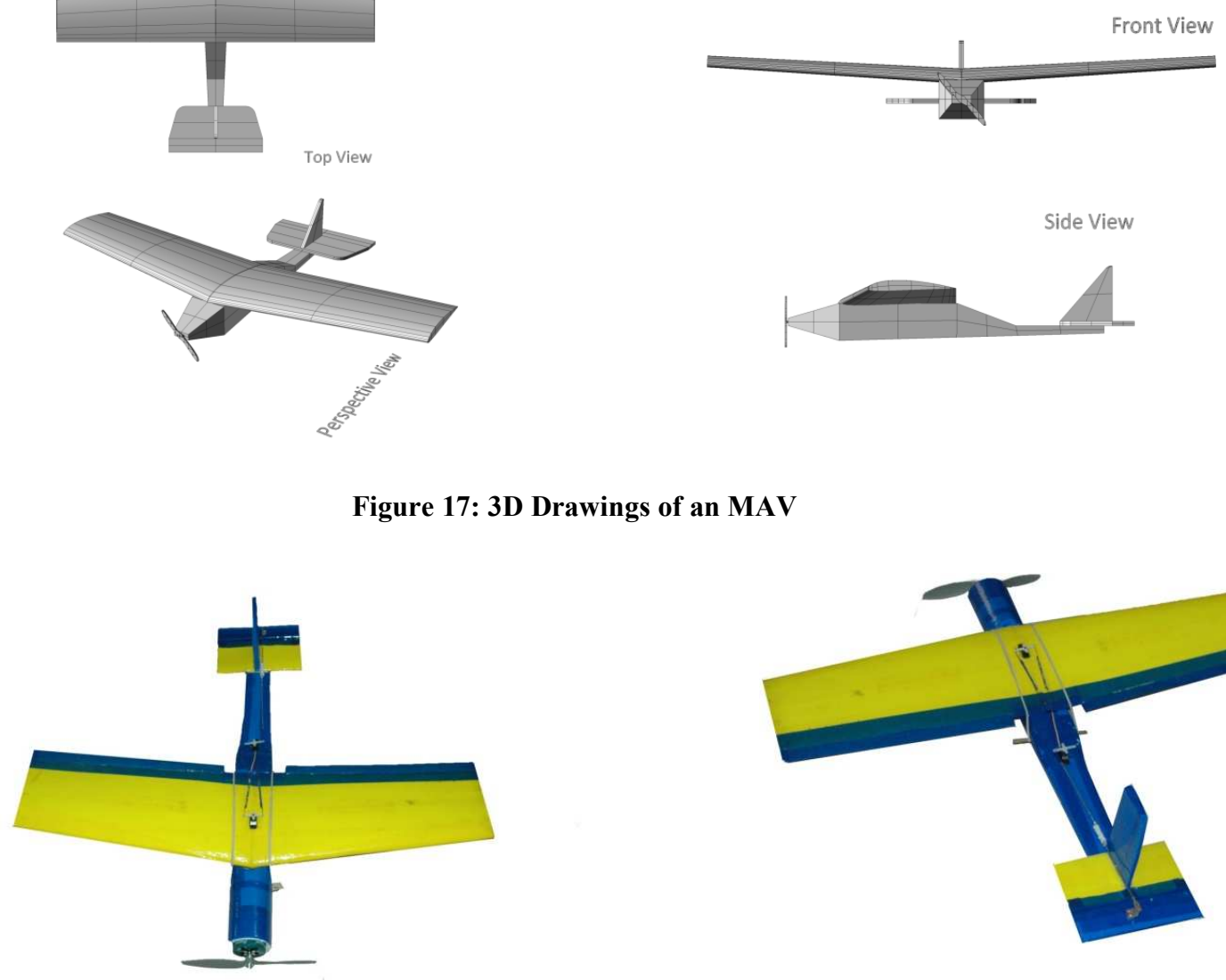

Side View

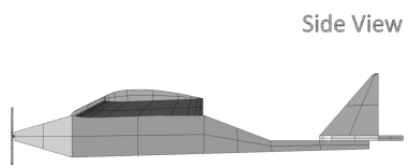

Figure 18: A complete MAV manufactured by the researchers 


\subsection{Prototype Photograph}

Final development and manufacturing of the prototype was done according to above analysis and research. The photographs of the prototype are given in the fig. 17-18.

\subsection{CONCLUSION}

The aim of the project was to develop and demonstrate a practical method of designing an MAV. Micro aircraft present a number of unique challenges such as aerodynamics and systems integration and thus require a different design approach from those applied to standard-sized aircraft. The aerodynamic theory used to predict performance of MAVs still needs to be investigated in greater detail as it does not allow the designer to predict the performance with sufficient accuracy in some cases. The wind tunnel tests, which were not carried out as a part of the project, due to some limitations, needs to be carried out in future, which is very efficient in proving various aerodynamics aspect. Two wing planforms tested in the hypothetical manner needs more practical tests. The rapid optimization of the MAV's geometry within given constraints has proven to be an extremely effective method of designing a micro-sized aircraft.

\section{REFERENCES}

[1] G. Torres and T. Mueller, "Aerodynamic Characteristics of Low Aspect Ratio Wings at Low Reynolds Numbers, Proc. of the Conf. on Fixed, Flapping, and Rotary Wing Vehicles at Very Low Reynolds Numbers", Notre Dame University, pp. 278305, 2000.

[2] W. Shyy, D. A. Jenkins and R. W. Smith, "Study of Adaptive Shape Airfoils at Low Reynolds Number in Oscillatory Flows", AIAA Journal, vol. 35, pp.1545-48, 1997.

[3] Marek, P., Smrcek, L.; "Development of DART MAV - Fixed Wing Hover-Capable Micro Air Vehicle", Advanced Engineering Design Conference, Prague, Czech Republic, June 2006.

[4] Watkins, S., et al., "Atmospheric Winds and Their Implications for Micro air Vehicles”, AIAA Journal, Vol.44, No.11, November2006.
[5] M. J. Khan, M. T. Iqbal and S. Mahboob, " $A$ wind map of Bangladesh", September 2008.

[6] Bohorquez, F. et al. "Design, Analysis and Performance of a Rotary Wing MAV", Smart Structures Laboratory, Alfred Gessow Rotorcraft Center, Department of Aerospace Engineering, University of Maryland.

[7] Lennon, A., "Basics of $R / C$ Model Aircraft Design”, Air Age Inc., Ridgefield, CT, USA, 1996. 